\title{
MEDIUM TERM DEVELOPMENT OF RENEWABLE ENERGY
}

\author{
Emilio Menéndez Pérez \\ Mine Engineer, $\mathrm{PhD}$ \\ Honorary Professor in UPM and UAM
}

\begin{abstract}
Approach
Renewable energies appeared in the energy scheme as a result of the crisis of oil prices in the seventies. The Solar Platform of Almeria arouse in that awakening. Afterwards, in the latest decades the awareness for such a need has been strengthened and now it is linked to all kinds of problems posed by conventional energy such as nuclear accidents as Three Mille Island o Chernobyl, disasters such as the one occurred with the Prestige and the disaster which is progressively surrounding us with the "climate change", or finally oil and natural gas wars as the one we are living in Iraq.
\end{abstract}

In such a context, renewable energy cannot be a mere photograph for politicians and businessmen to make environmental marketing or a short-term business with; they are a need for mankind. And to that extent, they should be developed in full, and this means working hard in the technological development, and the brief analysis of such a development is the purpose of this document.

However, renewable energies should be developed in crystal-clear collaboration with less favoured countries. Renewable energies are low-intensity shows of the energy that comes out from the sun, and they should be concentrated in order to be used conventionally and those places in the Earth where this is feasible will be mainly large areas in Third World Countries.

If massive use of fossil fuels by citizens of the first world is resulting in the huge social distortion that the climate change is and will be, we should pay in order to solve such a problem. The use of conventional energy in developed countries should bear strong taxes so that a cleaner development out of the appropriate funds may be attained for less favoured countries which were exploited throughout History.

The sacking of peoples, as for instance what occurred with gold and silver in America, with other types of wealth, from ivory to cocoa or minerals, and as oil and natural gas was throughout the twentieth century and probably continues being: as in Iraq since 1920, in Afghanistan wars since the eighties, the cold war in Angola or what is currently happening in Nigeria or Ecuador, not to mention so suitable examples as the Chaco War from 1932 to 1935, cannot be repeated with renewable energy. Some history books and some newspaper libraries show as how we should not act again.

\section{Energy Options}

The development of renewable energy sources should be planned with the aim that at the end of the twenty-first century, when the best or maybe most of hydrocarbon fields will have been exhausted, 
then they may be a real and main energy option. This idea can be based in three foundations which pose technological and management problems. Chart no. 1.

a) Eolic Energy. Nowadays it appears as an option to generate electricity which may come to the point of meeting the demand of mankind, due to the resources volume worldwide. An annual recoverable potential of more than $50,000 \mathrm{TWh}$ is estimated, while the current demand is $15,000 \mathrm{TWh}$.

The big problem is that it has variable availability in the energy vector and it is mainly located in distant areas. On the one hand, this will force the introduction of electricity storage technologies, hydrogen production or other actions in the future and on the other hand, it will imply big investments on infrastructures for transporting energy.

Electricity generation should already be progressively developed since this decade, with the idea that the power of $25,000 \mathrm{MW}$, which is currently installed throughout the world, may have been multiplied by fifty in the year 2020, which would mean producing only the fifth part of the world electricity demand.

The big development should start in the third decade of this century with the aim of having several million MW of installed power, in order to produce electricity and hydrogen massively, the latter in order to be used by land and air transports.

b) Biomass. Biomass has accompanied Humanity continuously, at the beginning for everyone and now for poorer ones. It has two possible uses: fuel for heat and electricity, which is a necessary option for developing countries, and its technological availability is wide though it can be improved; the other use is biofuels for transport, which should increase its technological capacities appreciably.

We should bear in mind that the possible negative effect of biomass development for social and environment issues, may be important: such as the sequestration of land which should be used to produce food, aggression to biodiversity due to monocrops, unfair trade of vegetable matters, etc. Therefore, we should be cautious with this option. Its energy potential is not very high and it should be considered as a transitional and aid option to less favoured countries, though it may also be applied to developed countries.

c) Solar energy. It is the main energy source, but it is the one with a lower degree of energy intensity. That is the reason why the concentration process is the most expensive when one tries to obtain electricity out of it. The alternatives of water and fluid heating are feasible options, which are already being applied and have a good level of technological development, though it can be improved.

Electricity production has different alternatives: parabolic collectors, mirrors, Stirling dish and photovoltaic energy. In all cases it is an expensive option, with high specific investments. The last two of these alternatives do not need cooling water and are modular approaches, what lets us think about wide future developments. But in any event, they require strong technological development.

Solar energy, either with the said technologies or other, should be a well-developed option by the year 2025 with the purpose of producing electricity and hydrogen, the latter either by electrolysis or by means of other alternatives such as photonic dissociation. 


\section{Eolic Energy}

The development of the eolic technology began in the United States under a new energy view of President Carter, someone so missed nowadays. Its development shows some working lines for next years:

- Increase in the aerogenator unitary power. The commercial level is above $750 \mathrm{~kW}$, precommercial machines are in $2 \mathrm{MW}$, and expectations point to $5 \mathrm{MW}$.

- Increase in the efficiency of eolic energy collection: rotor variable speed, application of new options of power electronics, new designs for electric generators.

- Suitable materials for the new and big machines, particularly in the rotor blades, but also in other parts.

- New conceptions of aerogenerators optimizing the ratio investment and recovered energy; different options are feasible both in the horizontal axis as in the vertical axis.

- Technologies for electricity storage implying two working lines: materials allowing high accumulation intensities for different designs, power electronics of high response to electricity charge and discharge.

- Hydrogen production by electrolysis systems with high energy efficiency, of moderate specific investment and easily regulated according to the excess electricity availability in the energy system. Figure no. 1.

\section{Liquid Biofuels}

This is an alternative widely used in Brazil and the USA, two countries which due to different circumstances obtained large surpluses of cane sugar and cereals. In Europe, specific energy crops are being developed, generally cereal grains or oily seeds in order to transform them into bioalcohol or biodiesel. Here the limited availability of space for crops and the heterogeneous nature of soil and climate conditions make it necessary to develop new options in order to have raw materials and ad hoc processes. Research lines are aimed at:

- Developing energy crops with a good ratio of energy recovery versus the necessary inputs for its growing.

- Processes geared to obtaining alcohols out of tubers or cellulose or hemicellulose materials. Acid hydrolysis or enzymatic hydrolysis or other treatments.

\section{Solar Energy}

Obtaining solar electricity implies the use of a wide area of transformation in the processes currently available, more than $10 \mathrm{~m}^{2}$ per $\mathrm{kWp}$ of power, in the best location. The basic research lines should be aimed at reducing that area, or what is the same, increasing the performance of 
energy transformation, either by means of concentration processes or by using new materials in some cases, or a combination of both.

To that extent, different scientific fields will be involved. The developments in optics will be essential in those lines of concentration of solar energy in order to have the simultaneous effect of "several suns" on the same transformation device. The materials being used will be developed, both regarding concentration systems and regarding final collectors of solar energy. On the other hand, it will be necessary to work in the electronic techniques of electric current inversion and conversion.

Nowadays, the options of parabolic collectors and mirrors are the ones having economic parameters which are closer to the levels to make the massive presence of electricity produced in the network feasible. Production costs are four to six times those corresponding to conventional systems with fossil fuels. However, the expectations for a deep technological change are limited, though imaginative solutions may appear.

Photovoltaic and Stirling dish technologies move away from market parameters for connection to the network. Its costs are between eight to fifteen times those of conventional production. Nevertheless, we can find here important options for technological and industrial transformation, both in new materials, in concentration designs and in mass production and high mechanization plans.

In any event, it is necessary to accept that producing electricity with solar energy will have higher costs than those currently dealt with in the market. But in this case we should take into account that the serious environmental effects of conventional methods of energy transformation have not been internalized.

\section{Technological Management}

Energy research in the world has fallen appreciably since the implantation of liberalizing energy management systems in the different countries. The first need is to increase again the allocation of funds and, if possible, a good programme of international collaboration to that purpose.

It is not easy that energy and equipment companies, taking into account the way they manage in the liberalized market, may set up wide scope programmes. That is the reason why country governments should be the engine for developing deep actions, and in our case preferably from the European Union, coordinating the working groups of the member states and regions.

The space availability in Europe shows that we cannot be self-sufficient in renewable energy, as we are not in conventional energy. As a whole, we import half of the energy we use, and some countries like Spain, three parts out of four. That is the reason why from the beginning we should think about collaboration plans with large eolic areas and others with solar development areas, and in general collaboration with all the peoples and regions in the world.

Madrid this March 19th 2003

On the eve of 
Figure $N^{o} .1$.- Electricity and hydrogen production chart

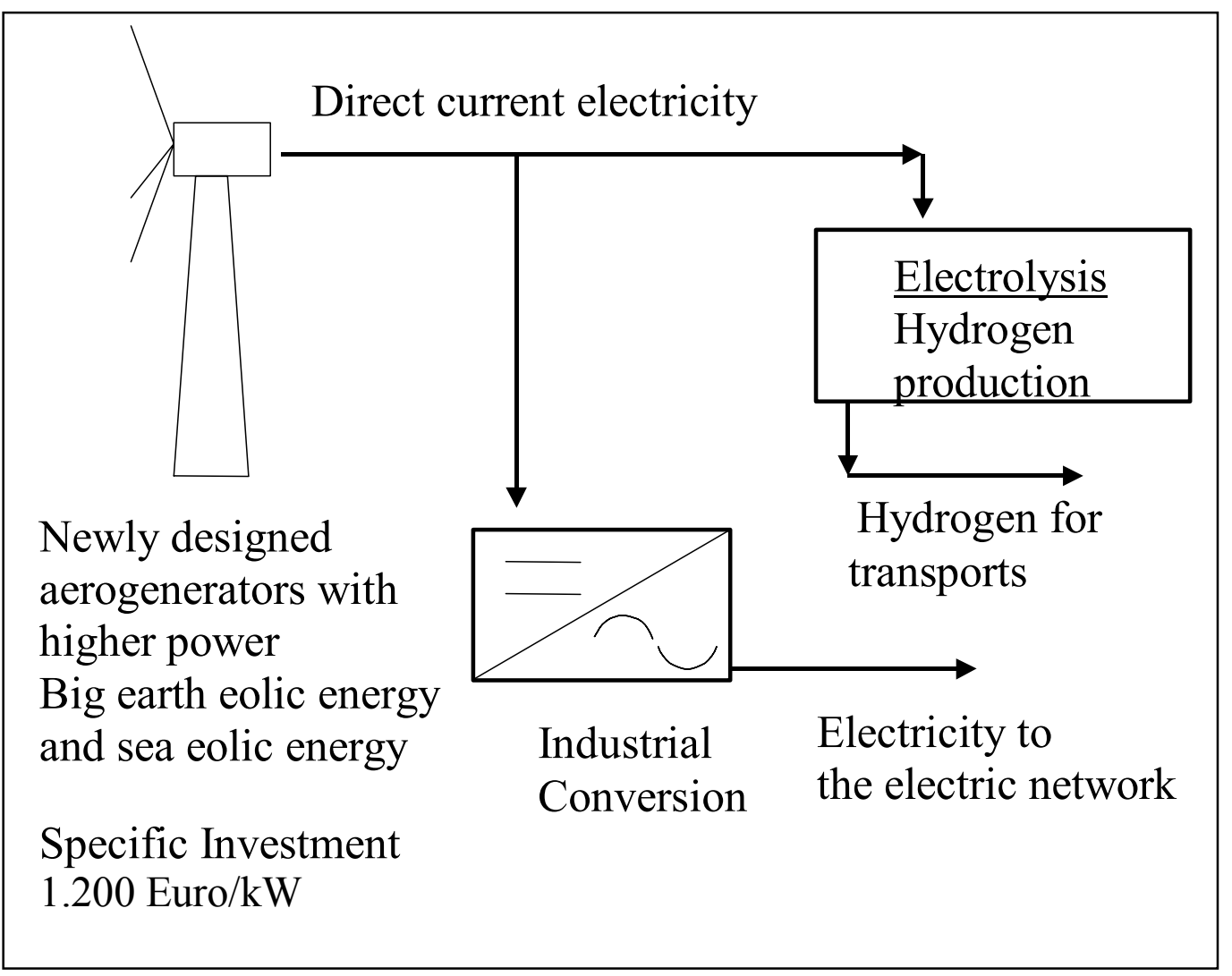




\begin{tabular}{|c|c|c|c|}
\hline Renewable Energy & $\begin{array}{l}\text { Short-term development } \\
\text { Till the year } 2010\end{array}$ & $\begin{array}{l}\text { Medium-term development } \\
\text { From } 2010 \text { to } 2020\end{array}$ & $\begin{array}{l}\text { Long-te } \\
\text { From } 20\end{array}$ \\
\hline Eolic Energy & $\begin{array}{l}\text { Electricity generation } \\
\text { Installed Power } \\
\text { - } \quad \text { Spain: } 13,000 \mathrm{MW} \\
\text { - } \quad \text { Europe: } 150,000 \mathrm{MW}\end{array}$ & $\begin{array}{l}\text { Electricity and beginning of hydrogen } \\
\text { production. } \\
\text { - } \quad \text { Spain: } 40,000 \mathrm{MW} \\
\text { - World: } 1,000,000 \mathrm{MW}\end{array}$ & $\begin{array}{l}\text { Hydrog } \\
\begin{array}{l}\text { From } 1 \\
\text { electric }\end{array} \\
1 / 3 \text { of th } \\
\text { transpor }\end{array}$ \\
\hline Liquid Biofuels & $\begin{array}{l}\text { Meeting European commitments. } \\
\text { - Spain: } 6 \% \text { of the demand of fuels } \\
\text { for transports. }\end{array}$ & $\begin{array}{l}\text { Moderate growth in the Spanish and } \\
\text { European production. } \\
\text { Collaboration in the increase in } \\
\text { production in third countries. }\end{array}$ & \\
\hline Electricity from solar sources & $\begin{array}{l}\text { Electrification programmes in remote } \\
\text { areas in developing countries. } \\
\text { Symbolic implantation in developed } \\
\text { countries, with a green and exemplary } \\
\text { nature. }\end{array}$ & $\begin{array}{l}\text { Growth of installed power in order to } \\
\text { reach: } \\
\text { Spain: } 5,000 \mathrm{MW} \\
\text { World: } 200,000 \mathrm{MW}\end{array}$ & $\begin{array}{l}\text { Strong } \\
\text { of reachi } \\
\text { Spain: } 5 \\
\text { World: } 1\end{array}$ \\
\hline
\end{tabular}

Chart $\mathrm{N}^{\circ}$. 1.- Possible outline for the development of renewable energy. Optimistic option. 